\title{
Appraisal Based Learning for Effective Cognition of Vernacular Architecture
}

\author{
Ar. Asif R Khan, N. Lakshmi Thilagam
}

\begin{abstract}
-one of the objectives of architectural design education can be defined as mentoring architecture students to produce meaningful architecture. In concurrence a progressive divergent framework to facilitate effective learning is required. This could be achieved by adopting an instructional strategy which focuses on act of meaningful knowing. This approach would not only make transmission of learning contextually relevant, but may also significantly alter the perception of the habitable space to be conceived. The research further depicts the need for diachronic process based appraisal format of enquiry. The emphasis is on retrieval of information about effective building design strategies from past attempts with respect to a particular typology of habitat design. This knowledge base becomes basis for innovative problem addressal while resolving new spatial issues. Such a precedent based instructional strategy would pave way for meaningful architectural discourse in the design studio. A framework for appraisal based study is proposed as part of the research paper. A qualitative study of the fundamentals of traditional dwellings practices in Kerala is also carried out as part of this research. From the view point of perceiving and reflecting on built environment; the ability to recognise, understand and experience spaces in terms of appropriate settings, spatial quality, functionality and form is essential. The proposed instructional framework is further strengthened by integrating with fundamental concepts of learning theories and physiological activities related to teaching and learning based mentoring process. Essential traits from the three domains of learning theory namely behaviourism, cognitivism and constructivism are incorporated to construct a learning experience known as comprehensive approach. The understanding of human cognition and induced activity helps us to logically comprehend the various activities involved at respective stages during learning. This overall act relates to how rationally processed information is being organised in a person, how it is likely to be retrieved and applied for resolving spatial issues related to habitat design when given an opportunity.
\end{abstract} appraisal based learning, diachronic approach, sustainable practices

\section{RESEARCH PREFACE}

\section{A. Research Problem}

Appraisal based learning in architecture could significantly enhance learning experience, resulting in creation of knowledge base and know - how to adaptively

Revised Manuscript Received on December 05, 2019.

* Correspondence Author

Ar. Asif R. Khan *, Kalasalingam Academy of Research and Education, Krishnankoil, Tamil Nadu, India. Email: ar.asif.k@ gmail.com

Dr. N. Lakshmi Thilagam, Kalasalingam School of Architecture, Krishnankoil, Tamil Nadu, India. Email: hodbarch@klu.ac.in
Keywords: learning theories, comprehensive approach,

reuse progressive practices developed over time.

\section{B. Statement}

Develop a rational understanding about role of appraisal based learning in understanding the phenomenon of cognition with respect to architecture and identity in a given context.

\section{Objectives}

To externalise the fact that instructional strategies can enhance learning experience.

\section{Research Questions}

The primary research questions put forward as part of this research are:

- What is the role of intellective information processing in design discourse?

- Can emphasis on architectural discourse anchored to appraisal based learning with stress on vernacular sustainable environmental systems facilitate better cognition?

\section{E. Methodology}

The theoretical research format is identified for the framework of this particular study. Descriptive mode of approach is augmented by qualitative mode of study. The sequence of research plan is as follows:

- Review of Literature:

1) Review of basics of cognitive psychology.

2) Review of fundamental of instructional theories.

3) Review of contextual vernacular architecture practices.

- Develop critical perspective and theorise on the following:

1) Role of information processing in architecture pedagogy.

2) Role of divergent approaches in architectural instructional discourse.

3) Outline a framework for appraisal based study.

- Relevance of meaning formation and architectural imageability:

1) Role of information processing in architecture pedagogy.

2) Listing of progressive passive practices developed over time.

- Formulation of the role of precedent based instructional strategy in enhancing cognition and design discourse.

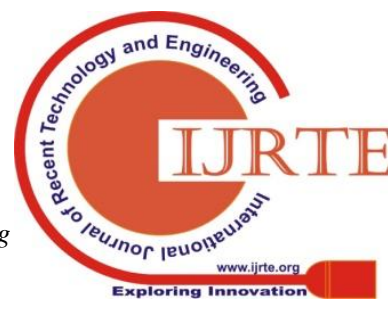




\section{INTRODUCTION}

Students should be given sufficient insights about what one needs to effectively consider in architectural built environments to develop proficient understanding.

To be critically aware of the progressive evolution of a settlement over time with proper appreciativeness of the contextual interpretations of habitat design along with due relevance for sustainability would help imbibe cognition of architectural language of space making. I suggest that architectural design pedagogy should be viewed as training toward the manifestation of the ability to conceptualize, coordinate, and execute the idea of building. This act must furthermore be rooted in humane tradition [1].

Architecture is a creative activity, evolved on the basis of spatial imprinting of human pre requisites for carrying out certain activities. The resultant spatial realm has its own expressive characteristics and architectural qualities of space making. It becomes relevant to critically appraise the habitat design in order to generate a review. Architectural identity is an underlying quality rather than an inherent quality. When he looks at a building, an image falls on the retina of his eye. This image, which is a result of a process as mechanical as photography, has no meaning to him unless his mind has interpreted it, and his feelings or his emotions have responded to it. This response is bound to vary from person to person depending upon his receptivity and intelligence. The observer's consciousness of architecture is therefore, as personal a matter as the architect's intention [2]. It's only upon identification that architectural expression of identity can manifest. These thoughts ratify that architectural crucial role in exploring architecture. The underlying act behind the whole process could be associated with act of intellective information processing.

\section{INTELLECTIVE INFORMATION PROCESSING}

With respect to built environment, when you observe a building, you are able to see and identify the building. Your perception helps to establish a linkage with the external world. To perceive the built environment in this way, requires that you posses concepts. This could be broadly described as ways of reception, understanding, integration and interpretation about the world. At this point we are discussing about the human ability to decode inputs from sensation followed by perception into tangible mental images, which help us to establish an interactive link with our surroundings and guide us in our activities. There is a need for development of this intellective information processing behaviour in an individual as it plays a critical role in inducing effective learning.

In general learning is emphasised by stressing on a relevant learning theory leading to knowledge attainment and reflection. A learning theory often becomes the basis for attributes along with knowledge base of an individual play a

the instructional approach adopted in a given setting to prescribe how to better help students learn. Such approaches result in critical development of psychomotor, cognitive and affective qualities in an individual. So it is significant that educators are aware of the basis and relevance of the relevant instructional approaches.

Table- I: Comparitive Analsyis of Approaches

\begin{tabular}{|c|c|c|c|}
\hline Activities & Behaviourism & Cognitivisim & Constructivism \\
\hline Learning & $\begin{array}{l}\text { Stimulus and } \\
\text { response }\end{array}$ & $\begin{array}{l}\text { Information } \\
\text { processing }\end{array}$ & $\begin{array}{l}\text { Processing and } \\
\text { reinforcement of } \\
\text { understanding based } \\
\text { on experiences }\end{array}$ \\
\hline $\begin{array}{l}\text { Type of } \\
\text { Learning }\end{array}$ & $\begin{array}{l}\text { Learning } \\
\text { occurs by } \\
\text { memorising or } \\
\text { by skill based } \\
\text { conditioning } \\
\text { and responding }\end{array}$ & $\begin{array}{l}\text { Learning } \\
\text { occurs through } \\
\text { internal } \\
\text { processing of } \\
\text { information }\end{array}$ & $\begin{array}{l}\text { Learning occurs by } \\
\text { problem solving in } \\
\text { hypothetical/realistic } \\
\text { and investigative } \\
\text { situations }\end{array}$ \\
\hline $\begin{array}{l}\text { Instructional } \\
\text { Strategies }\end{array}$ & $\begin{array}{l}\text { Present } \\
\text { material for } \\
\text { practice and } \\
\text { feedback }\end{array}$ & $\begin{array}{l}\text { Present new } \\
\text { information, } \\
\text { reiterate, } \\
\text { organise, } \\
\text { recollect and } \\
\text { apply }\end{array}$ & $\begin{array}{l}\text { Assist active and self } \\
\text { paced learning }\end{array}$ \\
\hline $\begin{array}{l}\text { Key } \\
\text { Concepts }\end{array}$ & Reinforcement & $\begin{array}{l}\text { Change in } \\
\text { Knowledge }\end{array}$ & $\begin{array}{l}\text { Discovery } \\
\text { realisation }\end{array}$ \\
\hline $\begin{array}{l}\text { Pedagogical } \\
\text { Anchorage }\end{array}$ & $\begin{array}{l}\text { Instructor } \\
\text { Centric }\end{array}$ & $\begin{array}{l}\text { Mutually } \\
\text { Reinforcing }\end{array}$ & Facilitation Centric \\
\hline
\end{tabular}

We will be preliminarily looking at such three approaches as part of this paper notably; behaviourism, cognitivism and constructivism. The behaviourist approach to this process was anchored to the notion of conditioning and emphasised on the relevance of training with focus on desired outcomes. When a particular stimulus-response (S-R) pattern is reinforced, the person is conditioned to respond [3]. Meanwhile the cognitive approach is concerned with how people acquire, store, retrieve, transform, and apply information to enhance understanding, resolve a problem or generate solutions. It concerns the way we take in information from the outside world, how we make sense of that information, and what use we make of it [4]. This overall act relates to how information is being processed and organised in a person, how it is likely to be retrieved and aplied for resolving spatial issues related to habitat design when given an oppurtunity. Progressiveness brought about the constructivist 
ideology; it is a learning theory which approaches the phenomenon of learning from an experiential and value based perspective which involves process of constructing knowledge rather than acquiring it directly. The fundamental grounding is based on notion of enquiry, exploration, and appraisal. Constructivist theory regards learning as an active process in which learners construct and internalise concepts, ideas and knowledge based on their own present and past knowledge and experiences [5].

Table 1 conveys a comparative analysis of approaches and the emphasising factors.

While emphasising the need for a well defined framework for instructional approach, the basis of review should start by provoking thought with respect to architectural values and character embedded in a built environment. This could be at micro-level constituted by individual level buildings or at macro level constituted by combination of buildings. Collectively micro as well as macro realms provide the morphological outlook to the contextual architectural character embedded in the built environment of a particular area. These statements affirm that the basic mannerism of experiencing architecture often elucidates the significance of totality. Great architecture and ambitious architectural theory relates architectural progress with social progress [6]. Such an outlook would help in gathering a theoretical, graphical and decisive knowledge about what constitutes architecture as a domain of creative pursuit and realisation. In order to achieve progressiveness as discussed a cohesive instructional approach integrating the fundamental concepts of cognitive theories and physiological activities related to teaching and learning based mentoring process should be in place. This would encourage the act of meaningful learning to take place.

\section{ACT OF MEANINGFUL KNOWING}

The basis of cognition is generally related to generating proficient understanding; generally this is achieved by unravelling the fundamentals. The overall act could be further explained as a process of appraisal based learning. Act of examining or assessing something in order to judge the significance, quality and value [7]. The way a person is able to understand, recognize and experience spaces and relate it to its spatial function, form and utilitarian quality is a matter of great importance in architecture. Keeping this notion in mind it becomes relevant to empower students with rational ability to critically appraise built environment they are in contact with. The overall understanding that's induced while critical appraisal is being done is essential to initiate the act of meaningful knowing. This could be achieved by development of a comprehensive approach which facilitates the same.

In general it is difficult to identify exactly which specific approach practitioners adopt in their instructional settings, since many may adopt aspects of various approaches to meet their individual needs. What we need in the field of instruction at the moment is a comprehensive model where all the indispensable elements involved in effective instruction are integrated [8]. Explicit integration of instructional discourse is often dealt by eclectic learning theory approach; to reinforce effective learning. Eclectic instructional design is the process whereby a designer blends ideas from multiple learning theories to construct a learning experience that works better than a course designed from only one theoretical influence [9]. This could be successfully achieved by integrating essential traits from the three domains of learning theory namely the behaviourism, cognitivism and constructivism; comprehensive approach. This would enable effective correlation of learning with human information processing mannerism. The integrative approach ensures activity based reasoning process to occur. As depicted in Table II three activities happen in a sequential manner while appraisal based learning is emphasised namely: objective information processing, subjective information processing and creative response.

Table- II: Integrative Approach Activity Sequence

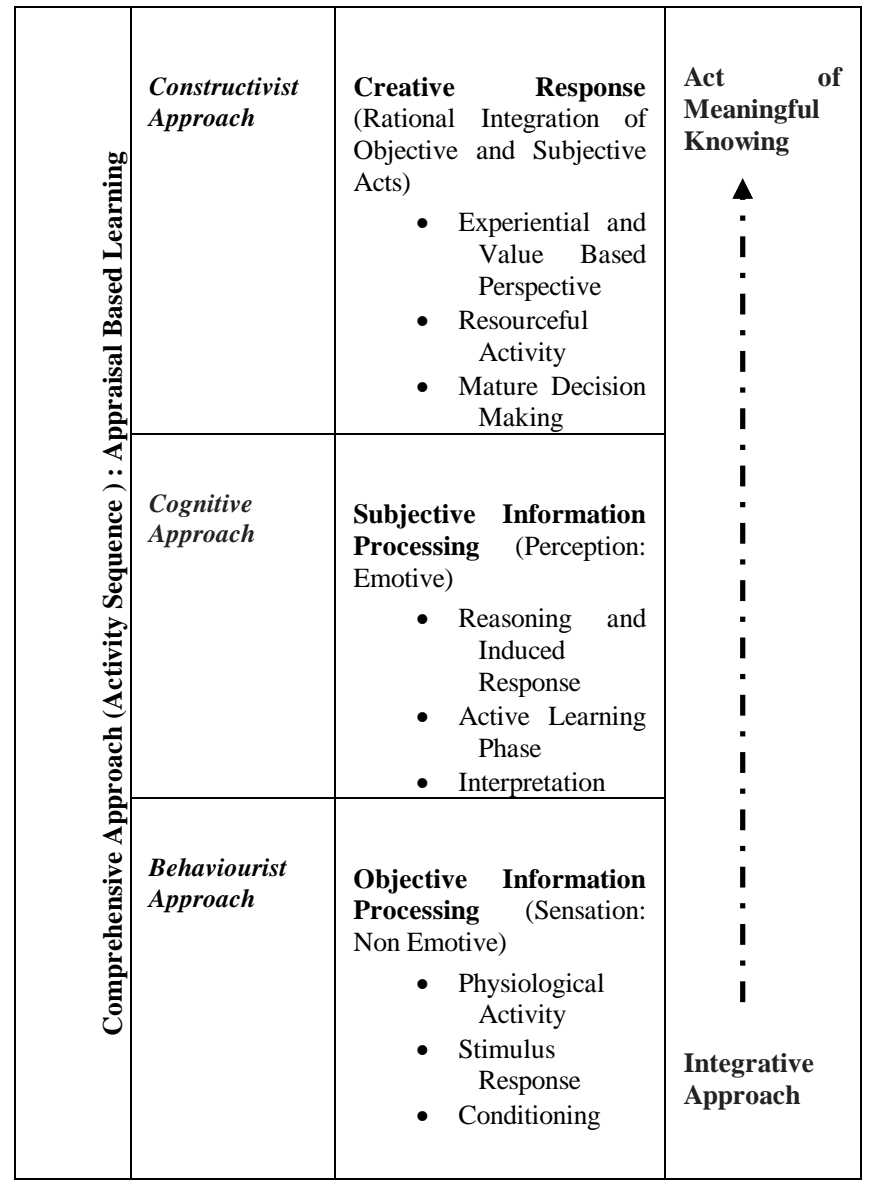

This would further pave the way for original and critical response, the trained union of objective and subjective information processing characteristics. Such approach induces the act of concept formation in the mind of the individual while interacting with his surroundings. The overall act however involves facilitation and orientation of the students. This would

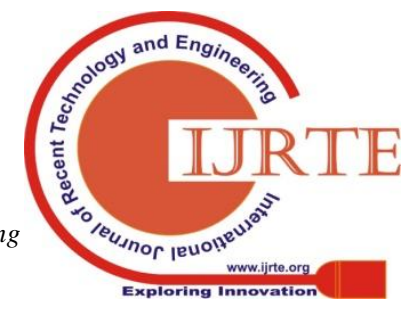


take time, space, and careful mentoring to disseminate the knowledge and creativity that are central to the process of meaning formation in an individual while dealing with built environment. Thereby aiding in the cognition of meanings and values that are assigned to the design principles and elements of architecture that make up built environment in the given context. If conditioned further in an effective manner they would realise the relevance of mutually reinforcing relationship between the human systems of subsistence and the ecosystem in the context of space making. Nevertheless the key factor in this process is the need of a well defined approach factor with emphasis on precedent knowledge based perspective.

\section{APPROACH FACTOR}

The appraisal format of learning emphasis on unravelling effective building design strategies embedded in vernacular buildings. Once this is achieved, creative minds would definitely be able to reinterpret the passive strategies in a modern context innovatively to bring about novelty. The relevance of correlating the approach to a particular context can be made by developing theories that provide effective interpretative understanding about the fundamentals involved. Theory is generally brought into being by a curious mind, individuals having or showing an interest in learning things and relying on rational methods to define them. The human activities involved in theory building are constituted by the following traits: exploration, unfoldment, discovery and refinement. As depicted in Fig.1 each activity paving way to the other, leading to gradual awareness and increase in an individual knowledge base. From the realms of known to the unknown and to the unexplored bringing about a sense of relevance of heuristic rationality in an individual.

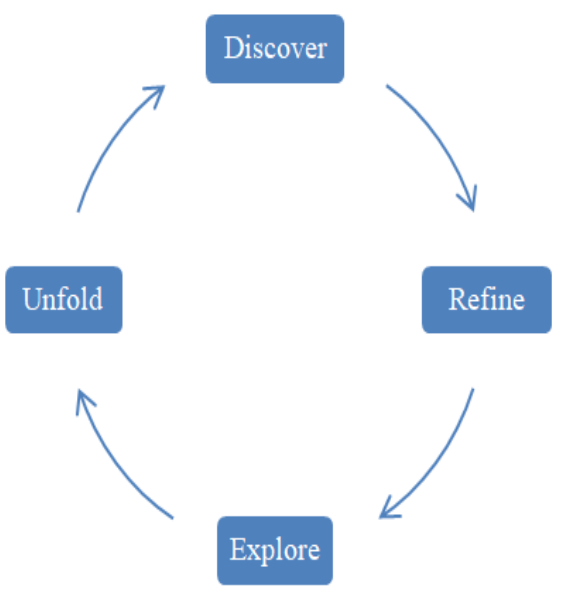

Fig. 1. Cognition Activity Sequence [10]

The fundamental anchoring notion of teaching - learning in architecture design studio could be specifically related to act of meaningful knowing. . In typical institutional learning environment, design learning happens in studios that are practical and mental agility, complex interaction of skills,

focused on a design problem. Students approach the design problem individually or collectively and their work is judged and reviewed by a design jury panel constituted of academicians and practicing architects. At this juncture it becomes relevant to understand that the basis of instructional discourse in a studio has to be linked to effective understanding of the stages of design development. Preliminary level architecture process is constituted by the following stages: spatial design issue or project task appraisal, conceptual design and detailed design. These stages are followed up by project execution level activities and continuance post design; maintenance stage in realistic settings. If the instructional discourse is based on comprehensive approach then sufficient importance is given to individuals cognitive activity sequence during the act of appraisal of existing buildings of similar typology to gain sufficient insights. The understanding of human cognition and induced activity helps us to logically understand the various activities involved at respective stages during critical appraisal. The overall process is cyclic, interconnected and progressive as indicated in the Fig. 2 paving way for self realisation and development of understanding about the built environment being critically appraised. It is configured in such a manner that it is rational and in order. It further helps the individual to approach conceptual design and detailed design with effective understanding of precedent attempts.

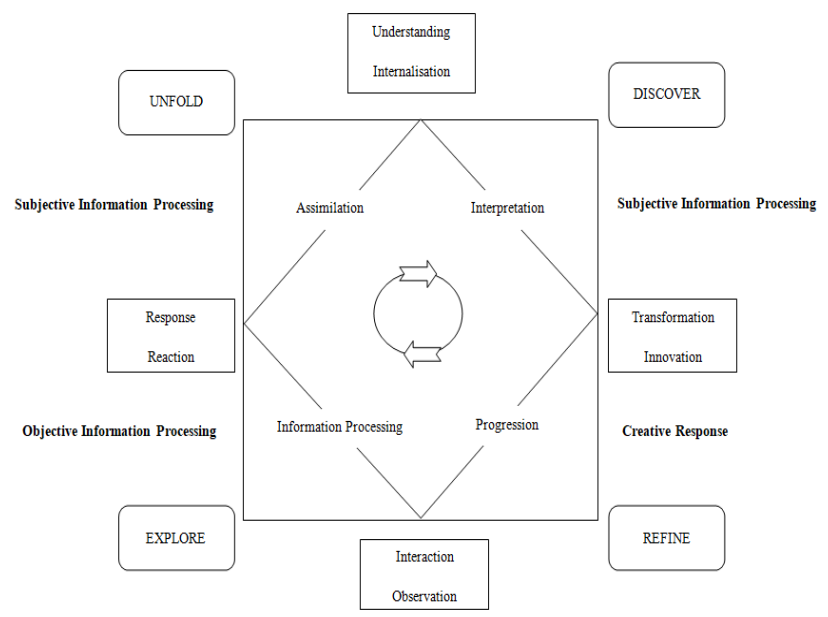

Fig. 2. Outline Framwork - Appriasal Based Study

Two directives are available under this notion of discourse namely diachronic and synchronic approach. The etymological grounding of the term diachronic and synchronic approach can be traced to anthropology and linguistics. Transdisciplinary application of the fundamental ideas put forward by these two terms can become basis for progressive architectural appraisal and design development. Depending on the approach option chosen, a visible influence is set to be made on the nature of solution derived. These acts however emphasise the need of a matured intellectively information processing constructive mind in the learner for properly choosing a course of action.

In simple words a scheme that emphasis on diachronic

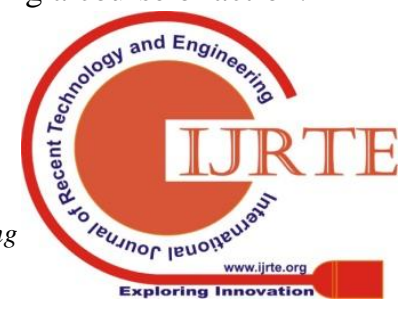


approach is one that examines the progression of something over time, allowing one to assess how that something changes throughout history. Meanwhile a synchronic approach examines a particular something at a given, fixed point in time. It does not attempt to provide ideation based on progression rather consider the current state, as it is and provides means for intervention. In this particular context the matter under review is architecture. Since the basic objective of architectural design education could be thought of as educating architecture students to produce meaningful architecture. It becomes necessary to communicate the actual meaning and attributes associated with the phenomenon of meaning formation and relevance of meaningful knowing. Such approaches would provide directionality in evolving identity, order and space in an appropriate manner elucidating an architectural character and language to the built environment.

\section{DIACHRONIC APPROACH BASED PEDAGOGY}

A precedent knowledge based perspective forms the basis of such an approach, where critical appraisal of architectural progression aids develop better cognition for effective act of meaningful knowing. In this particular context the case of a traditional dwelling design in Malabar region (northern half of the state of Kerala) is probed. The basis of dwelling design in our regional context has evolved from time immemorial, which highlights its uniqueness based on regional scriptures and preaching, treatises in ancient literature. Traditional regional architecture is vividly known for having its basis on Vaasthu Shastra. Vasthu Shasthra is the theory of the traditional building science of India which was formulated and developed through centuries of observation and practice. In the process it adapted to regional influences, and these regional versions had a great degree of autonomy. Vasthu Shasthra is derived from the root 'vas' meaning 'to dwell' or 'to occupy [11]. These writings are treatise on effective utilisation of natural resources and harmonious zoning principles for design of built environment.

The planning theory applied in the construction of a traditional dwelling in Kerala, commonly revolves around a general form of spatial grammar and pattern. The basic pattern of configuration of habitable spaces around a courtyard was grounded in refined canonical treatise. The incremental format of modular planning and construction techniques made it possible to configure the dwelling design effectively. It also further emphasis the concept of the Vasthu Purusha Mandala the cosmic diagram and related geomantic forms of spatial planning based on certain auspicious calculations. This energy field called mandala comprising grids, diagonals and nodes formed the building code for spatial planning, proportions, door and window positions and the functional layout in traditional domestic architecture [12]. Made up of a schematic diagram showing the cardinal direction on the four sides of a square and a man's figure drawn diagonally with his head in the North East, refer Fig. 3. An interesting fact about the grid is that it is not static; the man revolves around the square and completes a full circle in one year. This diagram represents the non - static nature of the site itself and the movement of the earth around the sun [13].

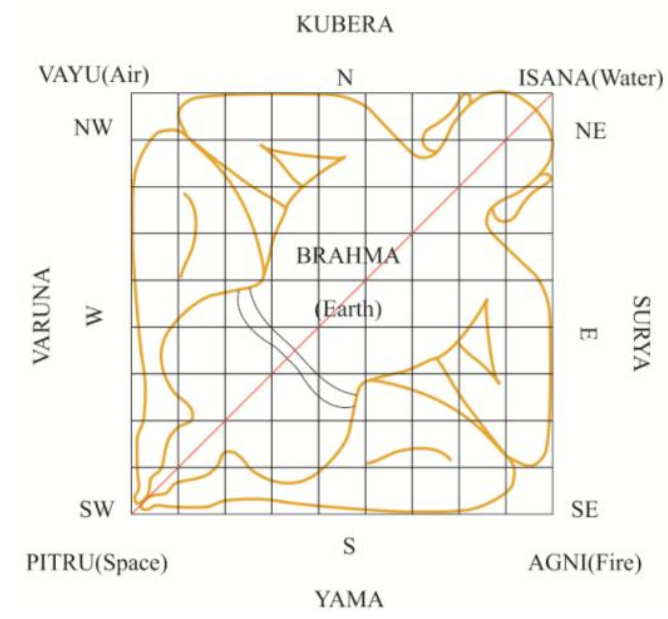

Fig. 3. Vasthu - Purusha Mandala

The overall size and number of rooms varied according to the social and financial stratification of the users. The smallest and basic dwelling unit is termed shala which in successive placement around a courtyard evolves into larger structures. In general there could be four types of configurations, namely: Ekashala, Dwishala, Thrishala and Chathurshala type, refer Fig.4. This planning theory is applied in the construction of a traditional dwelling in Kerala, commonly known as a Nalukettu, dwelling situated in a walled compound complimented by other supplementary structures. It was called Nalukettu because it was made up of four zones around a central courtyard, application of Mandala concept. The zones being: Vadakkini (facing north), Kizhakkini (facing east), Thekkini (facing south) and Padinjattini (facing west).

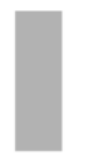

Ekashala

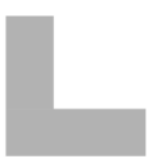

Dwishala

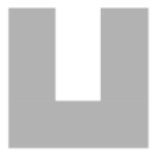

Thrishala

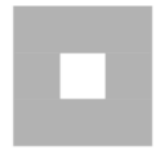

Chaturshala

\section{Fig. 4. Types of Shala Configurations}

In general the Nalukettu is made up of the following spatial zones. The entry to the dwelling is through Padippura, gate house at the entrance of the plot. Positioned usually on the western or eastern side of the plot, the scale and complexity varies based on the caste and prosperity of the owner of the dwelling. A pathway leads to the Poomukhom, the living area of the main dwelling complex. Seating provisions made up of timber known as Chaarupadi is provided along the Poomukhom. This is complimented by a colonnade around the main house with deep overhanging eaves regionally recognized as Irayam. Transitional circulation spaces are called Idanazhi, which links spaces. Further within is the core constituted by a courtyard and functional rooms located

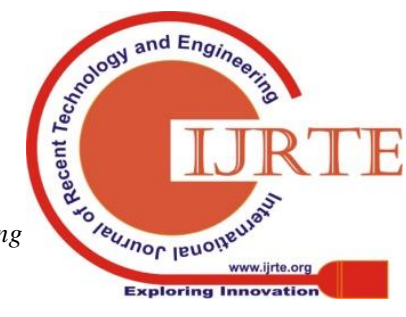


around it. This open to sky space is locally called Nadumuttam, the size of the opening is kept comparative to scale of the built form. Wooden stairs are normally provided to reach other floor and attic - known as Thattum - mukkal. The main structure is supplemented by auxiliary structures like Patthayappura (granary), Kulappura (Bathing Pond) etc [14].

Appraisal of a traditional dwelling, Poonthanam Illam at Perinthalmanna, Malappuram, Kerala refer Fig.5 gives insights about the form induced approach based on incorporation of tectonic principles of structural stability of a quadrangle induced form. The conscious presence of passive strategies that enhance human comfort index, active consideration of human ecology and bio-climatic design based innovative features pave way for intelligent additive subtractive realisation of built form incorporating regional construction principles and materials. These objectives have been incorporated by making use of the following features such as: natural ventilation, stack ventilation, solar shading, natural lighting, thermal insulation by design and construction practices,

rain water harvesting and others. These practices also have rational scientific linkages to modern scientifically proven concepts. Such a cohesive approach forms the focus principle for spatial realisation of the dwelling. The resultant iconic imageability of the dwelling is embodied with a sense of visual delight highlighting functional qualities.

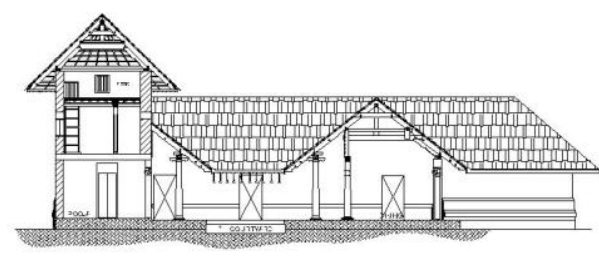

Section

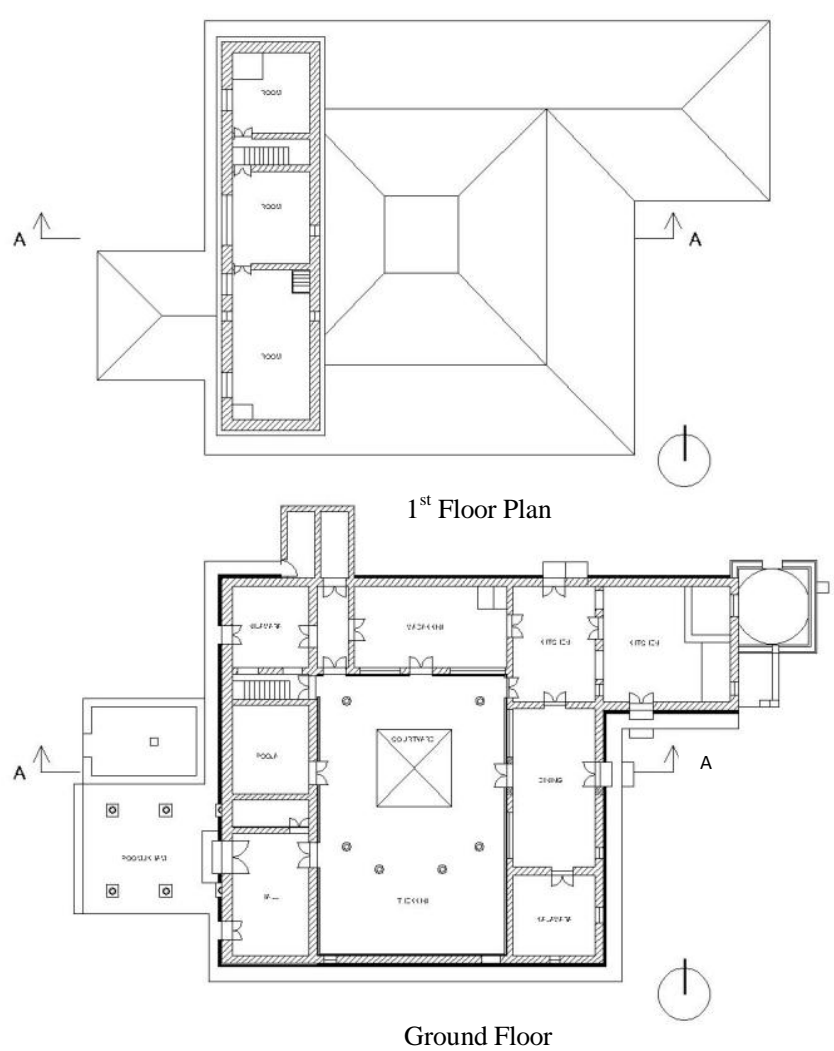

Ground Floor

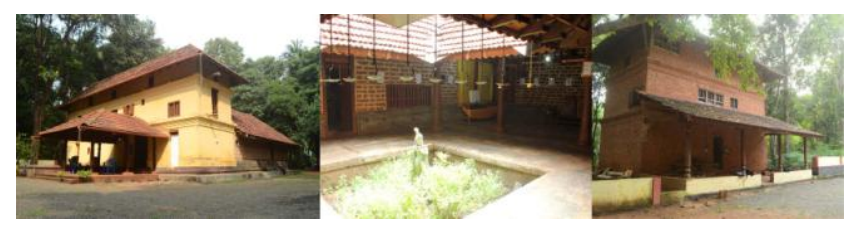

Fig. 5. Archetypal Vernacular Dwelling - Poonthanam Illam at Perinthalmanna

\section{CONCLUSION}

One of the objectives of architectural design education can be defined as mentoring architecture students to produce meaningful architecture. The research paper attempts at exploring the need of a progressive divergent framework to facilitate effective learning. With emphasis on integrating the fundamental concepts of cognitive theories and physiological activities related to teaching and learning based mentoring process. In accord a theoretical ideation with respect to an instructional model integrating essential traits from the three domains of learning theory namely the behaviourism, cognitivism and constructivism; comprehensive approach is proposed as part of this paper. This innovative pedagogical approach is further emphasised by the need of 
precedent knowledge based perspective to become the basis of experiential learning.

The precedent knowledge based perspective form of appraisal of habitat realm and resultant act of meaningful knowing would help envision studio pedagogical approaches in a rational manner when preparing students to develop a design e.g. in this particular scenario diachronic approach related to dwelling design is explored. If a studio is conducted on such a basis two major objectives are achieved. One is that it provides creation of significant knowledge base and secondly there is high probability for the students to retrieve information about effective building design strategies from past attempts with respect to a particular typology of habitat design and further innovate. This will definably help students to have better understanding of the requirements as well as to come up with a successful solution to address a given design problem. The studio pedagogue however is crucially responsible to facilitate environment for innovative transformational learning.

\section{REFERENCES}

1. Ashraf. M. Salama, "Knowledge and design: people-environment research for responsive pedagogy and practice," Procedia, Social and Behavioral Sciences, vol. 49, 2012, pp. 8-27.

2. S. A. Deshpande, Design Dialog: Dialectics of Design in Architecture. Delhi: Council of Architecture, 2013, p. 94.

3. M. Kehoe, Make That Grade Organisational Behaviour. Dublin: Gill \& Macmillan Ltd, 2013, Ch. 4.

4. D. Groome, An Introduction to Cognitive Psychology: Processes and Disorders. Hove: Psychology Press Ltd, 2004, p. 2.

5. Lawrence Manion, Keith Morrison, Dominic Wyse, and Louis Cohen, A Guide To Teaching Practice. New York: Routledge, 2010, p. 181.

6. P. Schumacher,(2002). What is an architect in society today? Hunch Magazine, [Online].No.5, [Accessed 115 2019]. Available: https://www.patrikschumacher.com/Texts/hunchsurveyresponse.htm

7. Cambridge Dictionary, [Online], [Accessed 206 2019]. Available: https://dictionary.cambridge.org/dictionary/english/appraisal

8. Ying-ying Cheng, Seiji Shibata, and Ching-chung Guey, "A triarchal instruction model: integration of principles from behaviorism, cognitivism, and humanism," Procedia Social and Behavioral Sciences, vol. 9, 2010, pp. 105-118.

9. Peter C. Honebein, and Darryl L. Sink, (2012, November, 21). The practice of eclectic instructional design. Performance Improvement [Online]. Volume 51, (10), pp. 26-31. [Accessed 2 July 2019]. Available: https://onlinelibrary.wiley.com/doi/abs/10.1002/pfi.21312.

10. Asif. R. Khan, "Human cognition induced urban realm - new directives," UIA 2017 Seoul World Architects Congress Book Of Abstracts, p.58.

11. D. A. Achyuthan, Readings in Vasthushasthra Traditional Architecture - Principles of Vasthushasthra. Calicut: Vasthuvidyapratisthanam, 1995.

12. J. J. Koduvelipararnbil, "Construction Practices in Traditional Dwellings of Kerala, India," School of Architecture McGill University, Montreal,199, p. 27.

13. V. Padmavathi, "Climatic architectural tradition of India," $1 s t$ International Conference on Passive and Low Energy Cooling for the Built Environment, Greece, 2005, pp. 1103 - 1108

14. Asif. R. Khan, "Aesthetical perception: conceptual realisation in design studio," International Conference Reinventing Design Pedagogy And Contextual Aesthetics: Thanima, Calicut, 2015.

\section{AUTHORS PROFILE}

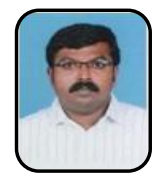

Ar. Asif R. Khan is pursuing his Ph.D in Architecture from School of Architecture, Kalasalingam Academy of Research and Education, Tamil Nadu, India. He acquired his B.Arch., degree from MES School of Architecture, Calicut University, Kerala and pursued his M.Arch., degree from SMMCA, Nagpur University, Maharashtra. He is recipient of the Netherlands Fellowship (NFP) to study the post graduate diploma course at Institute for Housing and Urban Development Studies, Erasmus
University Rotterdam. He has been associated with AA School London as a visiting teacher. Is a registered architect with Council of Architecture, India. Is a fellow member of Indian Institute of Architects. Has professional exposure in Middle East as well as in India on significant architectural projects. He has been associated with several architectural colleges in India. Has authored and presented numerous research papers at national and international forums. Presently officiating as Head of Institution at Al Salama Institute of Architecture, University of Calicut, Kerala, India.

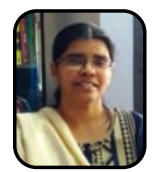

Dr. N. Lakshmi Thilagam is an Architect and Urban Designer and holds a $\mathrm{PhD}$ from the Indian Institute of Technology, Kharagpur, India. Her research interests are traditional urbanism, space syntax application for historic cities, heritage and urban conservation. She is currently conducting research to analyze the principles of sustainability exhibited in the traditional urban patterns of the historic cities of Tamil Nadu. As a passionate academician who has been teaching for the last 2 decades she also writes on the subject of Architectural education. 